Original Research

\title{
UJI AKTIVITAS ANTIBAKTERI SEDIAAN SABUN CAIR FRAKSI METANOL-AIR DAUN MANGKOKAN (Polyscias scutellaria (Burm.f.) Fosberg.) TERHADAP BAKTERI Staphylococcus epidermidis
}

\author{
ANTIBACTERIAL ACTIVITY TEST OF LIQUID SOAP PREPARATION OF \\ METHANOL-AIR FRACTION OF MANGKOKAN LEAVES (Polyscias scutellaria \\ (Burm.f.) Fosberg.) AGAINST Staphylococcus epidermidis BACTERIA
}

\author{
Khoirunnisa ${ }^{1}$ Rabima $^{2 *}$ \\ 1,2 Fakultas Farmasi, Universitas 17 Agustus 1945 Jakarta, Jakarta Utara, Indonesia, 14350 \\ *E-mail:rabima86@gmail.com
}

Diterima: 11/09/2019

Direvisi: 23/09/2019

Disetujui: 11/06/2019

\begin{abstract}
Abstrak
Kulit mempunyai fungsi untuk melindungi dari pengaruh luar. Sabun merupakan kebutuhan yang berguna untuk mandi, dan pembersih kebutuhan lain. Penelitian ini bertujuan untuk mengetahui aktivitas antibakteri fraksi metanol-air dan formulasi sabun cair fraksi metanol-air daun mangkokan terhadap bakteri Staphylococcus epidermidis, serta konsentrasi formula sabun cair terbaik dari hasil uji evaluasi. Daun mangkokan diekstraksi menggunakan etanol 70\% dengan metode maserasi hingga didapatkan ekstrak kental. Kemudian ekstrak kental ini difraksinasi dengan tiga pelarut yaitu n-heksan, etil asetat dan metanol. Dilakukan uji pendahuluan aktivitas antibakteri menggunakan metode disc diffusion pada fraksi etil asetat dan fraksi metanol-air, dari hasil yang didapatkan fraksi metanol-air memiliki zona hambat lebih besar dari fraksi etil asetat. Fraksi metanol-air diuji aktivitas antibakteri dengan tiga konsentrasi yaitu $5000 \mu \mathrm{g} / \mathrm{disk}, 6000 \mu \mathrm{g} / \mathrm{disk}$, dan $7000 \mu \mathrm{g} /$ disk dengan rata-rata zona hambat secara berurutan sebesar $11,30 \mathrm{~mm} ; 12,16 \mathrm{~mm}$; dan 13,20 mm. Selanjutnya dibuat sediaan sabun cair dengan empat variasi konsentrasi sebesar 0\% (F1 basis), 25\% (F2), 30\% (F3) dan 35\% (F4). Lalu diuji aktivitas antibakteri, hasil pengujian rata-rata zona hambat secara berurutan sebesar $0 \mathrm{~mm} ; 11,09 \mathrm{~mm} ; 11,94 \mathrm{~mm}$; dan 12,27 $\mathrm{mm}$. Formula sabun cair terbaik pada konsentrasi $30 \%$ dilihat dari hasil evaluasi.
\end{abstract}

Kata kunci: daun mangkokan (Polyscias scutellaria (Burm.F)Fosberg.); antibakteri; sediaan sabun cair; Staphylococcus epidermidis

\begin{abstract}
The skin has a function to protect from outside influences. Soap is a useful need for bathing, and cleaning other needs. This study aims to determine the antibacterial activity of methanol-water fraction and liquid soap formulation of methanol-water fraction of mangkokan leaves against Staphylococcus epidermidis bacteria, and the concentration of the best liquid soap formula from the evaluation test results. Mangkokan leaves were extracted
\end{abstract}


using $70 \%$ ethanol with maceration method until thick extracts were obtained. Then this thick extract is fractionated with three solvents namely n-hexane, ethyl acetate and methanol. Preliminary tests of antibacterial activity using the disc diffusion method on ethyl acetate fraction and methanol-water fraction, from the results obtained from the methanol-water fraction has a greater inhibition zone than ethyl acetate fraction. Methanol-water fraction was tested for antibacterial activity with three concentrations of $5000 \mu \mathrm{g} /$ disk, $6000 \mu \mathrm{g} /$ disk, and $7000 \mu \mathrm{g} /$ disk with an average inhibitory zone of $11.30 \mathrm{~mm} ; 12.16 \mathrm{~mm}$; and $13.20 \mathrm{~mm}$. then made liquid soap preparations with four variations of concentration of $0 \%(\mathrm{~F} 1$ basis), $25 \%(\mathrm{~F} 2), 30 \%(\mathrm{~F} 3)$ and $35 \%(\mathrm{~F} 4)$. Then tested for antibacterial activity, the results of testing the average inhibitory zone of $0 \mathrm{~mm} ; 11.09 \mathrm{~mm} ; 11.94 \mathrm{~mm}$; and $12.27 \mathrm{~mm}$. The best liquid soap formula at a concentration of $30 \%$ is seen from the evaluation results.

Keywords: Mangkokan leaves (Polyscias scutellaria (Burm.F) Fosberg.); Antibacterial; liquid soap preparations; Staphylococcus epidermidis

\section{PENDAHULUAN}

Bangsa Indonesia telah mengenal pengobatan secara tradisoinal, umumnya menggunakan tumbuhan, binatang, dan mineral. Secara umum kegunaan tumbuhan obat sebenarnya disebabkan oleh kandungan kimia yang dimiliki [1]. Daun mangkokan (Polyscias scutellaria (Burm.f.) Fosberg.) dikenal sebagai tanaman hias atau tanaman pagar, dan dapat pula ditemukan tumbuh liar diladang dan ditepi sungai. Berdasarkan pengobatan tradisional yang digunakan sebagai obat adalah bagian daun dari tanaman mangkokan. Daun mangkokan memiliki senyawa aktif berupa flavonoid, saponin, alkaloid, polifenolik. Dimana senyawa-senyawa tersebut memiliki mekanisme sebagai antibakteri [2].

Kulit merupakan organ yang menutupi seluruh tubuh manusia dan mempunyai fungsi untuk melindungi dari pengaruh luar. Kerusakan pada kulit akan mengganggu kesehatan manusia maupun penampilan [3]. Dalam kehidupan, sabun merupakan salah satu kebutuhan yang berguna untuk mandi, mencuci hingga pembersih kebutuhan lain. Di lingkungan banyak ditemukan sabun yang kandungannya menggunakan bahan kimia yang dapat membahayakan tubuh. Maka diperlukan pilihan lain untuk mengganti bahan baku kimia yang berbahaya yang berasal dari tanaman yang memiliki kandungan antimikroba.

Staphylococcus epidermidis merupakan bakteri gram positif, aerob atau anaerob fakultatif berbentuk bola atau kokus berkelompok tidak teratur, diameter $0,8-1,0 \mu \mathrm{m}$ tidak membentuk spora dan tidak bergerak, koloni berwarna putih, bakteri ini tumbuh cepat pada suhu $37^{\circ} \mathrm{C}$. Koloni pada pembenihan padat berbentuk bulat halus, menonjol, berkilau, tidak menghasilkan pigmen, berwarna putih porselin sehingga Staphylococcus epidermidis disebut Staphylococcus albus, koagulasi negatif tidak meragi manitol [4].

Untuk membuktikan khasiat dari daun mangkokan (Polyscias scutellaria (Burm.f.) Fosberg.), maka pada penelitian ini dilakukan pengujian aktivitas antibakteri dengan menggunakan fraksi metanol-air daun mangkokan (Polyscias scutellaria (Burm.f.) Fosberg.) terhadap bakteri Staphylococcus epidermidis. 


\section{METODE}

\section{Sampel (Bahan) Penelitian}

Daun mangkokan (Polyscias scutellaria (Burm.f.) Fosberg.) diambil dari Balai Penelitian Tanaman Rempah dan Obat (BALITRO) Bogor, etanol 70\%, etil asetatat, n-heksan, metanol, aquadest, Staphylococcus epidermidis, minyak zaitun, KOH, Na.CMC, asam stearat, parfum.

\section{Prosedur kerja}

Metode penelitian ini adalah penelitian eksperimental. Sampel pada penelitian adalah fraksi daun mangkokan (Polyscias scutellaria (Burm.f.) Fosberg.) yang dibuat dengan metode maserasi terlebih dahulu kemudian dilanjutkan dengan metode fraksinasi menggunakan tiga pelarut yaitu n-heksan, etil asetat dan metanol-air. Bakteri uji adalah Staphylococcus epidermidis. Metode yang digunakan adalah uji aktivitas antibakteri dengan metode difusi, dibagi menjadi 5 kelompok perlakuan dengan konsentrasi $5000 \mu \mathrm{g} /$ disk, $6000 \mu \mathrm{g} / \mathrm{disk}, 7000$ $\mu \mathrm{g} /$ disk dan 2 kelompok kontrol yaitu kontrol positif, kontrol negatif dengan pengulangan sebanyak 3 kali. Media agar untuk kelompok perlakuan menggunakan Blood Agar Plate (BAP), dan untuk pengujian kekeruhan suspensi bakteri dibandingakan dengan 0,5 Mc. Farland. Zona hambat yang terbentuk diukur dengan menggunakan jangka sorong.

\section{Uji Konsentrasi Hambat Minimum}

$5 \mathrm{~mL}$ media nutrient broth steril dalam tabung tambkan $1 \mathrm{~mL}$ dari masing-masing fraksi konsentrasi $(25 \%, 30 \%, 35 \%)$ dan $0,5 \mathrm{~mL}$ suspensi mikroba uji, kemudian semua tabung reaski dihomogenkan dan diambil sebanyak $2 \mathrm{~mL}$ untuk diukur nilai absorbansi Optical Density (OD) bakteri dengan menggunakan spektrofotometer UV-VIS $(\chi=600 \mathrm{~nm})$.

Tabel 1. Formulasi Sediaan Sabun Cair Fraksi Daun Mangkokan

\begin{tabular}{|c|c|c|c|c|}
\hline \multirow{2}{*}{ Nama bahan } & \multirow{2}{*}{ Kegunaan } & \multicolumn{3}{|c|}{ Komposisi } \\
\hline & & $\mathrm{F} 1$ & $\mathrm{~F} 2$ & F3 \\
\hline $\begin{array}{l}\text { Fraksi Daun } \\
\text { Mangkokan }\end{array}$ & Zat aktif & $25 \%$ & $30 \%$ & $35 \%$ \\
\hline Minyak zaitun & Basis minyak & $15 \mathrm{~g}$ & $15 \mathrm{~g}$ & $15 \mathrm{~g}$ \\
\hline Asam stearat & Penetral & $1,5 \mathrm{~g}$ & $1,5 \mathrm{~g}$ & $1,5 \mathrm{~g}$ \\
\hline Na.CMC & Pengental & $2 \mathrm{~g}$ & $2 \mathrm{~g}$ & $2 \mathrm{~g}$ \\
\hline Texafon & Pembusa & $1,5 \%$ & $1,5 \%$ & $1,5 \%$ \\
\hline $\mathrm{KOH}$ & $\begin{array}{c}\text { Membentuk basa } \\
\text { sabun }\end{array}$ & $8 \mathrm{~g}$ & $8 \mathrm{~g}$ & $8 \mathrm{~g}$ \\
\hline Aroma apel & Parfum & $1 \mathrm{~mL}$ & $1 \mathrm{~mL}$ & $1 \mathrm{~mL}$ \\
\hline Aroma coklat & Parfum & $0,5 \mathrm{~mL}$ & $0,5 \mathrm{~mL}$ & $0,5 \mathrm{~mL}$ \\
\hline Aquadest & Pelarut & $\begin{array}{l}\text { Ad } 100 \\
m L\end{array}$ & $\begin{array}{l}\text { Ad } 100 \\
\mathrm{~mL}\end{array}$ & $\begin{array}{c}\text { Ad } 100 \\
\text { mL }\end{array}$ \\
\hline
\end{tabular}




\section{Pembuatan Sediaan Sabun Cair}

Minyak zaitun dicampurkan dengan larutan $\mathrm{KOH}$ sedikit demi sedikit pada suhu 60$70^{\circ} \mathrm{C}$ hingga terbentuk pasta. Asam stearat, yang telah dilelehkan, dimasukkan dan diaduk hingga homogen. Dimasukkan Na.CMC yang telah dikembangkan dalam aquades panas, kedalam campuran. Campurkan texafon diaduk hingga homogen. Tambahkan fraksi mtanol-air daun mangkokan dan di aduk hingga homogen. Tambahkan aroma coklat dan aroma apel lalu diaduk hingga homogen. Selanjutnya, aquadest ditambahkan hingga $100 \mathrm{~mL}$ lalu di aduk hingga homogen, dan dimasukkan kedalam wadah [5].

\section{Uji Aktivitas Antibakteri Sabun Cair dengan Metode disc diffusion}

Pengujian antibakteri sabun cair menggunakan metode disc diffusion. Bakteri uji yaitu Staphylococcus epidermidis, pengujian dibagi menjadi 5 kelompok perlakuan dengan konsentrasi formulasi 25\%, 30\%, 35\% dan 2 kelompok kontrol yaitu kontrol positif yaitu dettol, kontrol negative yaitu basis sabun tanpa konsentrasi dengan pengulangan sebanyak 3 kali. Media agar untuk kelompok perlakuan menggunakan Blood Agar Plate (BAP), Zona hambat yang terbentuk diukur dengan menggunakan jangka sorong.

\section{Evaluasi Sediaan Sabun Mandi Cair}

a. Uji organoleptik

Meliputi pengujian fisik yaitu bau, warna, dan bentuk.

b. Pengujian $\mathrm{pH}$

Pengujian $\mathrm{pH}$ dilakukan dengan menggunakan $\mathrm{pH}$ meter. Nilai $\mathrm{pH}$ pada skala $\mathrm{pH}$ meter dibaca dan dicatat.

c. Uji tinggi busa

Sebanyak 1 g sampel ditimbang, dimasukkan kedalam tabung reaksi, ditambahkan aquades sampai $10 \mathrm{~mL}$, dikocok dengan membolak-balikan tabung reaksi, lalu diukur tinggi busa yang dihasilkan. Kemudian, tabung didiamkan selama 5 menit, dan diukur tinggi busa yang dihasilkan.

$$
\text { Uji busa }=\frac{\text { Tinggi busa akhir }}{\text { Tinggi busa awal }} \times 100 \%
$$

d. Pengujian viskositas

Pengukuran dilakukan dengan alat viskometer Brookfield $L V$ dengan spindle nomor 4. Kekentalan larutan diukur pada kecepatan $60 \mathrm{rpm}$. Hasil yang baik berkisar dari 400 sampai 4000 [6].

e. Pengujian daya sebar

Sebanyak 0,5 gram sampel diletakkan diatas kaca berskala, kaca lainnya diletakkan diatasnya dan pemberat 150 gram, selanjutnya didiamkan selama 1 menit. Dicatat diameter penyebaran dan hitung luas penyebaran. Hasil yang baik daya sebar berkisar dari 5,5 - 6,5 $\mathrm{cm}[7]$.

f. Uji homogenitas

Tiap formula sabun cair ditimbang sebanyak 0,1 gram. Diletakkan pada object glass, kemudian diamati dibawah mikroskop pada perbesaran 100 kali [8] 
g. Pengujian iritasi

Uji iritasi dilakukan dengan cara uji temple terbuka (patch test). Uji dilakukan selama 2 hari berturut-turut sebanyak 2 kali (pagi dan sore hari).

\section{Analisis Data}

Analisis statistik menggunakan uji normalitas dengan metode one way ANOVA dan dilanjutkan dengan metode Least Significant Different (LSD).

\section{HASIL DAN PEMBAHASAN}

\section{Uji Aktivitas Antibakteri}

Tabel 2. Hasil Zona Hambat Fraksi Methanol-air Terhadap Staphylococcus epidermidis

\begin{tabular}{|c|c|c|c|c|}
\hline & \multicolumn{3}{|c|}{ Diameter Zona Hambat (mm) } & Diameter Rata-Rata \\
\cline { 2 - 4 } Konsentrasi & Perlakuan & Perlakuan & Perlakuan & Zona Hambat $(\mathrm{mm}) \pm$ \\
KD
\end{tabular}

Berdasarkan hasil pengamatan, data menunjukkan besarnya zona hambat yang terbentuk dari fraksi metanol-air terhadap bakteri Staphylococcus epidermidis yaitu pada konsetrasi 5000 $\mu \mathrm{g} /$ disk sebesar 11,30 mm, pada konsentrasi $6000 \mu \mathrm{g} /$ disk sebesar 12,26 $\mathrm{mm}$ dan pada konsentrasi $7000 \mu \mathrm{g} /$ disk sebesar 13,20 mm. Berdasarkan penelitian [2] hasil dari ekstrak etanol $70 \%$ daun mangkokan pada konsentrasi $90 \%$ mendapatkan zona hambat sebesar 11,03 mm, yang artinya fraksi metanol-air lebih efektif memiliki daya hambat terhadap bakteri.

\section{Uji Konsentrasi Hambat Minimum}

Tabel 3. Absorbansi KHM Fraksi Methanol-air Terhadap Staphylococcus epidermidis

\begin{tabular}{|l|c|c|c|c|}
\hline Konsentrasi & Pengulangan I & Pengulangan II & Pengulangan III & Rata-rata \\
\hline $0000 \mu \mathrm{g} /$ disk & 0,804 & 0,805 & 0,801 & 0,803 \\
\hline $000 \mu \mathrm{g} /$ disk & 0,771 & 0,768 & 0,768 & 0,769 \\
\hline $000 \mu \mathrm{g} /$ disk & 0,738 & 0,742 & 0,741 & 0,740 \\
\hline
\end{tabular}


Berdasarkan nilai KHM yang didapatkan KHM terlihat pada konsentrasi $5000 \mu \mathrm{g} /$ disk yaitu hanya terjadi pertumbuhan bakteri namun sedikit, karena pertumbuhannya berhasil dihambat.

\section{Hasil Uji Aktivitas Antibakteri Sediaan Sabun Cair}

Tabel 4. Hasil Uji Aktivitas Antibakteri Sediaan Sabun Cair Fraksi Metanol-air Daun Mangkokan

\begin{tabular}{|c|c|c|c|c|}
\hline & \multicolumn{3}{|c|}{ Diameter Zona Hambat (mm) } & Diameter Rata-Rata \\
\cline { 2 - 4 } Formulasi & $\begin{array}{c}\text { Perlakuan } \\
1\end{array}$ & $\begin{array}{c}\text { Perlakuan } \\
2\end{array}$ & Perlakuan 3 & $\begin{array}{c}\text { Zambat (mm) } \pm \\
\text { SD }\end{array}$ \\
\hline F1 & 0 & 0 & 0 & $0 \pm 0$ \\
\hline Kontrol (+) & 12,16 & 11,76 & 12,30 & $12,07 \pm 0,28$ \\
\hline F2 & 10,71 & 11,39 & 11,16 & $11,09 \pm 0,34$ \\
\hline F3 & 11,88 & 11,83 & 12,11 & $11,94 \pm 0,149$ \\
\hline F4 & 12,21 & 12,17 & 12,43 & $12,27 \pm 0,14$ \\
\hline
\end{tabular}

Keterangan : Kontrol $(+)$ : dettol sabun cair

F1 (-) : formula sediaan sabun cair tanpa zat aktif

F2 : formula sediaan sabun cair dengan zat aktif $25 \%$

F3 : formula sediaan sabun cair dengan zat aktif $30 \%$

F4 : formula sediaan sabun cair dengan zat aktif $35 \%$

Hasil yang ditunjukkan pada pengujian aktivitas antibakteri sediaan sabun cair fraksi metanol-air daun mangkokan berdasarkan pengamatan, data menunjukkan besarnya zona hambat yang terbentuk dari sediaan sabun cair fraksi methanol-air pada bakteri Staphylococcus epidermidis yaitu pada formulasi $2(25 \%)$ sebesar $11,09 \mathrm{~mm}$, pada formulasi $3(30 \%)$ sebesar $11,94 \mathrm{~mm}$, dan pada formulasi 4 (35\%) sebesar 12,27 mm. Berdasarkan penelitian [5] hasil dari sediaan sabun cair yaitu adanya aktivitas antibakteri dalam sediaan sabun berdasarkan senyawa yang terkandung dalam ekstrak yang dipakai. 


\section{Hasil Evaluasi Sediaan Sabun cair}

a. Uji organoleptik

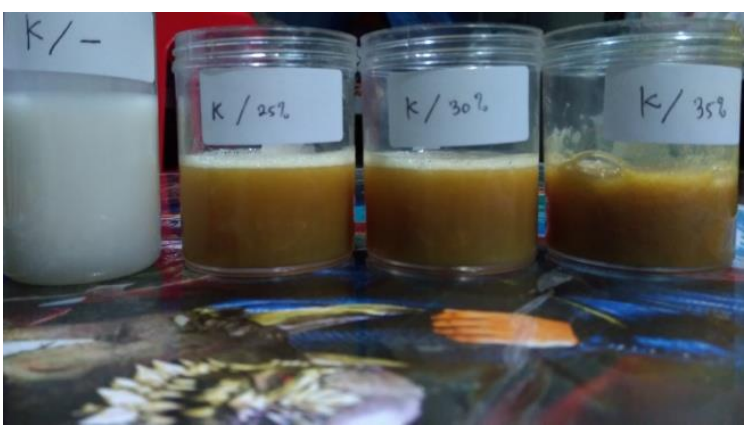

Gambar 1. Sabun Cair

Tabel 5. Hasil Pengujian Organoleptik Sediaan Sabun Cair

\begin{tabular}{|c|c|c|c|}
\hline \multirow{2}{*}{$\begin{array}{c}\text { Formulasi } \\
\text { sabun }\end{array}$} & \multicolumn{3}{|c|}{ Identifikasi } \\
\cline { 2 - 4 } F1 & $\begin{array}{c}\text { Lembut dan } \\
\text { kental }\end{array}$ & Coklat & Wurna \\
\hline F2 & $\begin{array}{c}\text { Lembut dan } \\
\text { kental }\end{array}$ & Apel & Coklat muda \\
\hline F3 & $\begin{array}{c}\text { Lembut dan } \\
\text { kental }\end{array}$ & Apel & Coklat \\
\hline F4 & $\begin{array}{c}\text { Lembut dan } \\
\text { kental }\end{array}$ & Apel & Coklat hampir tua \\
\hline
\end{tabular}

\section{b. Pengujian pH}

Tabel 6.Hasil Pengujian pH Sediaan Sabun Cair

\begin{tabular}{|c|c|c|c|c|}
\hline Formulasi & Minggu 1 & Minggu 2 & Minggu 3 & Minggu 4 \\
\hline F1 & 9,14 & 9,08 & 9,08 & 9,05 \\
\hline F2 & 9.08 & 9.08 & 9,05 & 9,05 \\
\hline F3 & 9,08 & 9,08 & 9,08 & 9,08 \\
\hline F4 & 9,08 & 9,08 & 9,08 & 9,08 \\
\hline
\end{tabular}

pH yang didapatkan dari sediaan sabun cair fraksi metanol-air daun mangkokan sudah sesuai dengan syarat yang telah ditetapkan oleh Standar Nasional Indonesia (SNI 06-4085-1996) [9] yaitu berkisar antara $8-11$. 


\section{c. Pengujian tinggi busa}

Tabel 7. Hasil Pengujian Tinggi Busa Pada Sediaan Sabun Cair

\begin{tabular}{|c|c|c|c|}
\hline \multirow{2}{*}{$\begin{array}{c}\text { Formulasi } \\
\text { sabun }\end{array}$} & \multicolumn{3}{|c|}{ Identifikasi } \\
\cline { 2 - 4 } & $\begin{array}{c}\text { Tinggi busa } \\
\text { awal }\end{array}$ & Setelah 5 menit & Kestabilan busa \\
\hline F1 & $15 \mathrm{~cm}$ & $13 \mathrm{~cm}$ & $86,7 \%$ \\
\hline F2 & $15,5 \mathrm{~cm}$ & $14 \mathrm{~cm}$ & $87,5 \%$ \\
\hline F3 & $15 \mathrm{~cm}$ & $13 \mathrm{~cm}$ & $86,7 \%$ \\
\hline F4 & $15,5 \mathrm{~cm}$ & $13,5 \mathrm{~cm}$ & $87,1 \%$ \\
\hline
\end{tabular}

Syarat tinggi busa yang ditetapkan pada Standar Nasional Indonesia (SNI 06-40851996)[9] yaitu sebesar $13 \mathrm{~mm}$ - $220 \mathrm{~mm}$. Pada penelitian ini pengujian tinggi busa telah memenuhi persyaratan yang ditetapkan Standar Nasional Indonesia (SNI 06-4085-1996)[9].

\section{d. Pengujian viskositas}

Tabel 8. Hasil Pengujian Viskositas Sediaan Sabun Cair

\begin{tabular}{|c|c|c|}
\hline Formulasi & Kecepatan $(\mathbf{r p m})$ & Kekentalan \\
\hline F1 & $60 \mathrm{rpm}$ & 900 poise \\
\hline F2 & $60 \mathrm{rpm}$ & 1300 poise \\
\hline F3 & $60 \mathrm{rpm}$ & 1250 poise \\
\hline F4 & $60 \mathrm{rpm}$ & 1150 poise \\
\hline
\end{tabular}

Nilai viskositas yang baik telah ditentukan yaitu berkisar antara 400 - 4000 poise. Dari hasil penelitian yang didapat viskositas sediaan sabun cair telah sesuai dengan syarat yang telah ditentukan [6].

\section{e. Pengujian daya sebar}

Tabel 9. Hasil Daya Sebar Sediaan Sabun Cair

\begin{tabular}{|c|c|c|c|c|c|}
\hline Formulasi & Minggu 0 & Minggu 1 & Minggu 2 & Minggu 3 & Minggu 4 \\
\hline F1 & 62,27 & 62,27 & 62,30 & 62,32 & 62,30 \\
\hline F2 & 63,07 & 63,05 & 63,00 & 63,05 & 63,05 \\
\hline F3 & 63,18 & 63,20 & 63,20 & 63,20 & 63,20 \\
\hline F4 & 64,21 & 64,15 & 64,15 & 64,20 & 64,20 \\
\hline
\end{tabular}

Pada seluruh konsentrasi formulasi didapatkan hasil daya sebar yang baik karena sesuai dengan literatur menurut [7] daya sebar yang baik yaitu 5,5-6,5 cm. Daya sebar dipengaruhi oleh tingginya viskositas, semakin tinggi nilai viskositas maka daya sebar semakin kecil. 


\section{f. Pengujian homogenitas}

Tabel 10. Hasil Pengujian Homogenitas Sabun cair

\begin{tabular}{|c|c|c|c|c|c|}
\hline Formulasi & Minggu ke & Minggu ke & Minggu ke & Minggu ke & Minggu ke \\
& 0 & 1 & 2 & 3 & 4 \\
\hline F1 & Homogen & Homogen & Homogen & Homogen & Homogen \\
\hline F2 & Homogen & Homogen & Homogen & Homogen & Homogen \\
\hline F3 & Homogen & Homogen & Homogen & Homogen & Homogen \\
\hline F4 & Homogen & Homogen & Homogen & Homogen & Homogen \\
\hline
\end{tabular}

Dari hasil yang didapat pada seluruh konsentrasi formulasi memiliki homogenitas yang baik dilihat dari pengujian minggu 0 sampai minggu ke 4 .

\section{g. Pengujian iritasi}

Tabel 11. Hasil Pengujian Iritasi Sediaan Sabun Cair

\begin{tabular}{|c|l|c|c|c|c|}
\hline \multirow{2}{*}{ No. } & \multicolumn{1}{|c|}{ Nama } & \multicolumn{4}{|c|}{ Formula } \\
\cline { 3 - 6 } & & F1 & F2 & F3 & F4 \\
\hline 1 & Rheni & - & - & - & + \\
\hline 2 & Yuli & - & - & - & + \\
\hline 3 & Suci & - & - & - & - \\
\hline 4 & Riska ayu & - & - & + & + \\
\hline
\end{tabular}

Jika ada iritasi pada kulit manusia biasanya timbul gejala gatal-gatal, kulit kemerahan, gatal dan yang paling parah yaitu pembengkakan, ditandai dengan tanda positif pada tabel, dan bila tidak terjadi iritasi ditandai dengan tanda negatif pada tabel.

\section{Hasil Uji Analisa Data}

Dari hasil uji normalitas didapat nilai sig $>\alpha$, yaitu $0,05 \quad(\mathrm{P}>0,05)$ yang merupakan syarat sebuah data dikatakan normal [10]. Sedangkan dari hasil uji homogenitas didapat nilai sig 0,180 dimana nilai ini lebih besar dari $\alpha 0,05(\mathrm{P}>0,05)$ yang merupakan syarat sebuah data dikatakan homogen. Kedua hasil uji tersebut memenuhi syarat maka uji one-way anova dapat dilakukan. Hasil uji one way anova didapat nilai signifikansi $<0,05$ sehingga dapat dikatakan terdapat perbedaan daya hambat yang signifikan secara statistik pada setiap kelompok perlakuan.

Hasil uji post hoc LSD memperlihatkan bahwa setiap kelompok perlakuan memiliki perbedaan yang signifikan, dengan perbedaan mean difference paling besar yaitu antara kelompok kontrol positif klindamisin dengan kelompok negatif dan perbedaan mean difference paling kecil yaitu antara kelompok fraksi 35\% dengan kelompok kontrol positif klindamisin.

\section{KESIMPULAN}

Pada penelitian ini dapat disimpulkan bahwa fraksi metanol-air diuji aktivitas antibakteri dengan tiga konsentrasi yaitu $5000 \mu \mathrm{g} /$ disk, $6000 \mu \mathrm{g} /$ disk, dan $7000 \mu \mathrm{g} /$ disk dengan rata-rata 
zona hambat secara berurutan sebesar $11,30 \mathrm{~mm} ; 12,16 \mathrm{~mm}$; dan 13,20 mm. selanjutnya dibuat sediaan sabun cair dengan empat variasi konsentrasi sebesar 0\% (F1 basis), 25\% (F2), 30\% (F3) dan $35 \%$ (F4). Lalu diuji aktivitas antibakteri, hasil pengujian rata-rata zona hambat secara berurutan sebesar $0 \mathrm{~mm}$; 11,09 mm; 11,94 mm; dan 12,27 mm dan masuk kedalam kategori sedang dilihat dari tabel zona hambat. Formula sabun cair terbaik pada konsentrasi $30 \%$ dilihat dari hasil evaluasi sediaan.

\section{DAFTAR RUJUKAN}

1. Hariana; H.arief. Tumbuhan Obat dan Khasiatnya. Seri 2. Jakarta : Penebar Swadaya; 2008.

2. Galuh Hanum R.; dan Syahrul A. Sabun Ekstrak Mangkokan (Nothopanax scutellarium Merr.) Sebagai Antibakteri Terhadap Staphylococcus aureus. Surabaya. Stigma Journal of Science 10, 2017 (1); 36-39.

3. Purwaningsih S.; Salamah E.; Budiarti T.A. Formulasi Skin Lotion dengan Penambahan Karagenan dan Antioksidan Alami dari Rhizophora mucronata Lamk. Jurnal Akuatika. 2014, Vol.5 No.1.

4. Jawetz; Melnick; Adelberg. Mikrobiologi Kedokteran. Edisi 20. Jakarta: EGC; 2001.

5. Sari R.; Ade F. Pengujian Aktivitas Antibakteri Sabun Cair dari Ekstrak Kulit Daun Lidah Buaya. Pharm Sci Res ISSN, 2017, 2407-2354.

6. Nauli A.P.; Darmanto Y.S.; Susanto E. Karakteristik Sabun Cair Dengan Penambahan Kolagen Ikan Air Laut yang Berbeda. J Peng Biotek Has, Pi 4, 2015.

7. Abu F.A.; Yusriadi; Tandah M.R. Formulasi Sediaan Sabun Cair Antibakteri Minyak Atsiri Daun Kemangi (Ocinum Americanum L.) dan Uji Terhadap Bakteri Staphylococcus epidermidis dan Staphylococcus aureus. Galen. J. Pharm, 2015, 1, 1-8

8. Mutmainah M.; Franyoto Y.D. Formulasi dan Evaluasi Sabun Cair Ekstrak Etanol Jahe Merah (Zingiber Officinale Var Rubrum) Serta Uji Aktivitasnya Sebagai Antikeputihan. E-Publ, Fak.Farm, 2015, 12, 26-32.

9. Dewan Standarisasi Nasional (DSN). SNI 06-4085-1996. Sabun Mandi. Dewan Standarisasi Nasional, Jakarta, 1996, 2-5.

10. Siswanto V.A. Belajar Sendiri SPSS 22, Yogyakarta, 2015. 